how do you evaluate ocean models when the data bases are incomplete and otherwise imperfect? What is an optimum mix of satellite sensors and orbits. plus drifting and moored buoys, floats, and ships-of-opportunity to achieve an ocean nowcast or acoustic propagation prediction?

When significant progress has been made with developing mesoscale eddy-resolving ocean prediction systems, system analyses of ocean-acoustic prediction systems, and coupling atmospheric and oceanic models, the Institute anticipates modeling marine ecosystems. In the meantime, the conduct of ocean OSSEs (Observing System Simulation Experiments) is a major research objective. The ocean OSSEs will allow quantification of the value for mesoscale ocean prediction of one proposed observing system network versus another, and they will facilitate the orderly design of such networks.

To facilitate the conduct of OSSEs, as well as the demonstration of ocean prediction systems, INO plans to initiate the Experimental Center for Mesoscale Ocean Prediction (ECMOP), which will be an INO-based organization and activity for establishing, maintaining and operating community libraries of models and data bases on the Class VII supercomputer.

Overall, INO is an unprecedented institution with initiative that will afford both the Navy and academia with exceptional opportunities to move ahead in the era of numerical models. supercomputers, digital telecommunication networks, satellite and acoustic remote sensing, telemetering insitu data networks, and increased understanding of ocean processes. Conceptually, the creation of the Institute recognizes that we have neither perfect models nor complete data sets: yet, using optimal estimation theory, models and data can be combined through data assimilation to provide improved estimates of oceanic fields on a regular basis, which in turn will support the advance of scientific inquiries, as well as the practical exploitation and management of the ocean.

As the Institute succeeds, it will add to the vitality and viability of the ocean sciences community through stimulation of the development of needed infrastructure in operational oceanography (because model products will need to be produced routinely in operational centers), which, in turn, will create new demand for graduates and research results, and new commercial opportunities and means to conduct ocean resource management.

\title{
Germany's New Research Center FOR MARINE GEOSCIENCES (GEOMAR)
}

\section{By Stephanie Pfirman}

GEOMAR was founded in June 1987 as an institution dedicated to marine geosciences and technological development. The institution consists of three interacting organizations: the Research Center for Marine Geosciences, the "Technologie GmbH." and the Technology Park. The GEOMAR Research Center for Marine Geosciences is central to this new institution. The director of the Research Center is Joern Thiede. Its four departments are:

- Marine Environmental Geology, Erwin Suess. Head. Emphasis is organic chemistry, in particular the anthropogenic and environmental influences on sea floor environments and changes in geotechnical properties of sea floor sediments.

- Paleoceanography, Joern Thiede, Head. Emphasis is the geologic development of the oceans, and the attendant development and circulation of water masses with biological and sedimentological influence.

- Marine Geophysics (selection of Head is proceeding). Emphasis is the development of continental margins and ocean basins, using reflection seismic profiling and modeling of marine geodynamics.

- Petrology of Oceanic Crust (Head position to be advertised). Emphasis is magmatic and volcanic processes associated with formation and development of oceanic crust.

The "GEOMAR Technologie GmbH" operates the Study Center and the Technology, Service and Development Center. Dr. Harald Baecker is its managing director. Under the auspices of the ChristianAlbrechts University, Kiel, the Study Center will offer advanced education and training in marine geosciences. Education will also be provided for land geologists, marine-geology technicians, and for research diving. Researchers from third-world countries will be offered developmental assistance.

Stephane Pfirman, GFOMAR, W ischhofistr 1-3. Bldg 4. D-2300 Kial 14. Federal Republic of Germany
The Technology. Service and Development Center will provide support services for the Research Center and thereby ensure rapid transfer of research and development experience to the field of applied geology. The Center manages a marine-geoscientific equipment supply, the research and development laboratories and workshops, and a sample and data archive. It provides outfitting and equipment operation for research expeditions. The Center develops, maintains and operates monitoring systems and stations. carries out sea floor surveys, and develops new instrument systems for the departments of the Research Center.

The GEOMAR Technology Park will be developed around the Research Center and "Technologie GmbH." Kiel was chosen as the location for GEOMAR because the Christian-Albrechts University and its associated Institut für Meereskunde together have the highest concentration of researchers in marine disciplines in Europe. They provide an unparalleled academic environment that permits GEOMAR to begin work at the highest level. The city of Kiel is located on a fjord open to the western Baltic Sea, with easy access for research ships of all nations. GEOMAR has a 500m-long dock suitable for most ocean-going research vessels. The Technology Park will be located directly across the fjord from the Institut für Meereskunde and the University. GEOMAR personnel now have their offices in one of the few historical buildings in the fish market that survived World War II. This building and an adjacent one are being refurbished to accommodate the first scientists. With a budget of approximately 55 million DM (nearly \$30 million U.S. dollars), a $6.000 \mathrm{~m}^{2}$ building will be constructed starting in the fall of 1989. By 1991. 40 positions for scientists are expected to be filled and 20 for technical and support personnel. By 1994. GEOMAR institutes will involve several hundred employees. including project-related appointments. 